\title{
Strength and Stiffness of Artificial Organic Soil Admixed with Lime Zeolite
}

\author{
Felix, N. L. Ling ${ }^{1,2, a}$, Khairul Anuar Kassim ${ }^{1, b}$, \\ Ahmad Tarmizi Abdul Karim ${ }^{2, c}$, and Jing Hui, Kan $^{1}$ \\ ${ }^{1}$ Faculty of Civil Eng., Universiti Teknologi Malaysia (UTM), Malaysia \\ ${ }^{2}$ Faculty of Civil \& Env. Eng., Universiti Tun Hussein Onn Malaysia (UTHM), Malaysia \\ afelix@uthm.edu.my, ${ }^{\text {b }}$ kanuar@utm.my, ctarmizi@uthm.edu.my
}

Keywords: unconfined compressive strength, $E_{50}$, organic soil, lime, zeolite

\begin{abstract}
Chemical stabilizers especially calcium based stabilizer, namely lime and cement had been widely used to modify and stabilize the soil. Extensive studies were carried out by researchers to improve the effectiveness and cost-benefit of stabilizers by introducing various types of blended lime and cement. Unconfined compressive test (UCT), one of the most simple and quick strength tests, is commonly used by researchers to indicate the suitability and successfulness of newly introduced stabilizer. The aim of this study is to establish the relationship and correlation of unconfined compressive strength and tangent modulus, E at 50\% of unconfined compressive strength of artificial organic soil admixed with lime zeolite. Two types of artificial organic soils, which named as Type A and Type B were prepared manually by mixing commercial kaolin with humic acid powder in different percentages. The artificial organic soils were admixed with blended lime zeolite in different ratio and cured for 7, 28 and 56 days in an oven with controlled temperature of $50^{\circ} \mathrm{c}$. The strength of the materials were determined by compressing the specimens using a UCT testing frame and the tangent modulus, E50 were calculated by plotting a linear slope at 50\% of ultimate strength over stress-strain curve. The findings of the study showed that the strength and E50 are strongly correlated and important as the indicator of rigidity of the material as well as its capability to resist compressive load.
\end{abstract}

\section{Introduction}

Organic soils are widespread in Malaysia, with about 2.7 million hectares, covering about $7 \%$ of the land surface [1]. Organic soils are basically characterized by high Cation Exchange Capability $(\mathrm{CEC})$, a high carbon over nitrogen $(\mathrm{C} / \mathrm{N})$ ratio, low nutrient contents, low bearing capacity and high compressibility [2]. The reduction in strength and stiffness of organic soils cause bearing capacity failure and excessive settlement, and thus leading to severe damage to buildings and foundations. Stabilization of soft soil by incorporation of lime is a technique widely used throughout the world to improve its use in construction. Generally, the stabilization behavior of mixing soil with lime can be attributed to the flocculation of soil particles that aggregates and accumulate together to form larger size particles or to create new materials due to pozzolanic reactions of lime with soil minerals [3,4]. However, lime was found to be less effective when dealing with organic materials [2]. Therefore many methods of soil treatment or soil stabilization had been invented to improve the organic soil towards higher strength and better stability. Application of blended lime-zeolite which is prepared by partial replacement of lime with zeolite in artificial organic soil was studied and shown quite encouraging findings [5]. Natural zeolite is identified as one of the most promising natural high quality pozzolans [6] and widely used in cement industry in China as a cement blending material.

The curing temperature is other parameter that can greatly influence the pozzolanic reactions. Higher temperatures accelerated the reaction process and increment of soil strength while low temperatures retarded this reaction or even caused it to stop [7, 8]. At room temperature, the pozzolanic reaction developed progressively and creates new bonds ( $\mathrm{CSH}$ and/or CAH) over a long 
period of time which in turn shown soil strength increases with time. Besides it, the stiffness of the stabilized materials is also in great interest of designer to determine its potential application.

Unconfined compressive test is a quick and cheap method that can be utilized to determine the strength of materials and its stiffness. The tangent modulus at $50 \%$ of its ultimate strength, which correspond to its shear strength, can be a quick guide to calculate its stiffness. High rigidity materials which always resulted in low strain failure and shown brittle failure mode, while low rigidity materials with high strain at failure will always associated with soft bulging upon failure.

\section{Materials and Methods}

Artificial organic soils with predetermined types of organic matter and organic contents were remolded in this study. Two types of artificial organic soils, which named Type A organic soil and Type B organic soil were differentiated by its organic content. Type A organic soil was prepared by admixing $70 \%$ of inorganic materials with $30 \%$ organic materials, while Type B organic soil was formed by admixing 50\% inorganic material with $50 \%$ organic matter manually based on its dry weight without taking into consideration its differences in density. One of the main objectives is to identify the effects of organic content on the properties of soil.

Humic acid was commonly used by researchers $[9,10]$ when preparing artificial organic soils in which humic acid is categorized as humidified organic matter [11]. Commercial grade powder humic acid utilized in this study was originally imported from China which normally used in agriculture to improve the soil which rich in alkali-salt. The powder humic acid is extracted from Leonardite- a naturally occurring, oxidized form of lignite coal, which sometimes described as the salts of humic acids admixed with mineral matter such as gypsum, silica, and clay.

Kaolin grade S300 marketed by Kaolin (M) Sdn. Bhd was utilized as inorganic material. Kaolin grade S300 was identified to be well graded with effective size, $\mathrm{D}_{10}$ of 4.53 micron [12]. The bulk chemical composition of the materials: Kaolin S300 and powder Humic acid were determined using X-Ray Fluorescence (XRF) and listed in Table 1. The chemical composition of materials was normalized to $100 \%$. The loss on ignition of the artificial organic soils at $440^{\circ} \mathrm{c}$ was determined as $18 \%$ and 29\%, respectively [5]. Based on Extended Malaysian Soil Classification System [13], the artificial organic soil Type A is classified as Slightly Organic Soil while artificial organic soil Type $\mathrm{B}$ is classified as Organic soil.

Table 1 Bulk chemical composition of raw materials [5]

\begin{tabular}{|c|c|c|c|c|}
\hline Composition (\%) & Kaolin S300 & Humic Acid & Lime & Zeolite \\
\hline $\mathrm{SiO}_{2}$ & 54.2 & 33.00 & - & 73.40 \\
$\mathrm{Al}_{2} \mathrm{O}_{3}$ & 40.8 & 24.60 & - & 12.50 \\
$\mathrm{SO}_{3}$ & - & 17.70 & 0.64 & - \\
$\mathrm{CaO}$ & - & 11.90 & 97.60 & 5.28 \\
$\mathrm{Fe}_{2} \mathrm{O}_{3}$ & 1.51 & 7.68 & - & 1.88 \\
$\mathrm{TiO}_{2}$ & 0.59 & 1.43 & - & - \\
$\mathrm{MgO}$ & 0.36 & 1.04 & 1.24 & 0.98 \\
$\mathrm{~K}_{2} \mathrm{O}$ & 2.21 & 0.84 & - & 4.47 \\
$\mathrm{Na}_{2} \mathrm{O}$ & - & 0.60 & - & 1.06 \\
$\mathrm{Cl}$ & - & 0.40 & - & - \\
$\mathrm{BaO}$ & - & 0.32 & - & - \\
$\mathrm{SrO}$ & - & 0.13 & - & - \\
\hline
\end{tabular}

The artificial organic soils were pre-mixed manually and remolded with optimum moisture content. The samples were prepared in constant density using stainless steel mould of inner diameter $50 \mathrm{~mm}$ and final height of $100 \mathrm{~mm}$ by referring to the respective standard $[14,15,16]$. Four types of additives which are Lime-Zeolite (10:0)-Additive 1, Lime-Zeolite (8-2)-Additive 2, LimeZeolite (5-5)-Additive 3 and Lime-Zeolite (0-10)-Additive 4 were utilized with the aim to improve 
the strength of the organic soils. The bulk chemical composition of the hydrated lime and natural zeolite were shown in Table 1.

The mass of each component (artificial organic soil, water in pore, additive, water for additive) was determined based on the approximation for the wet method of deep mixing [17]. The idealized phase diagrams of the soil before added with admixtures, slurry admixtures added and final product after mixing were shown in Fig. 1. The symbols used to represent volumes and weights/masses of the material are shown in the figure as well.

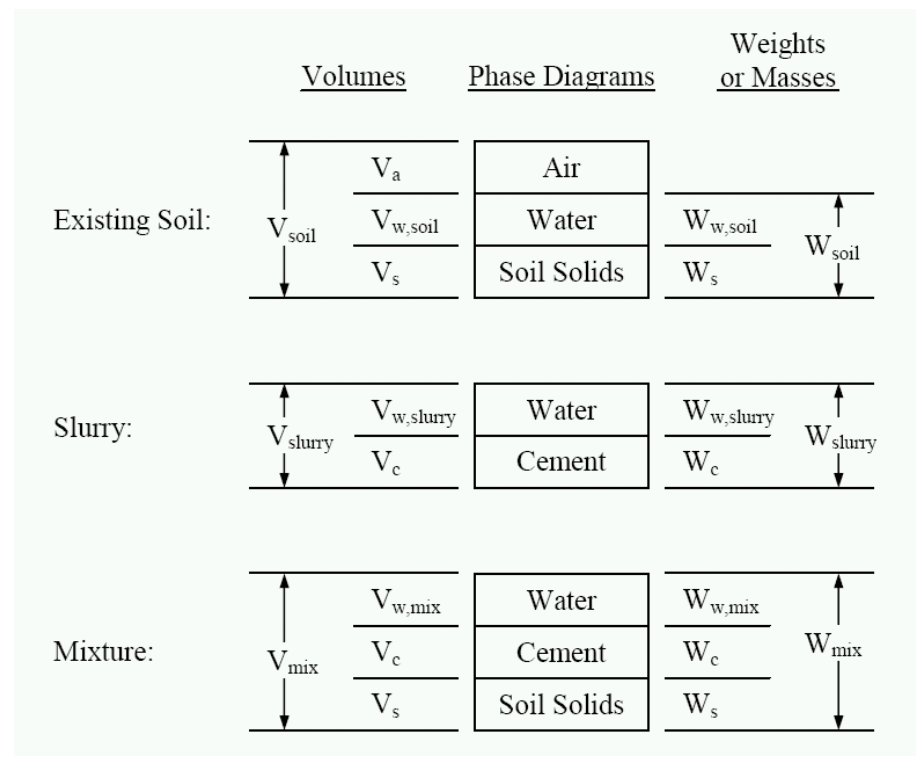

Fig. 1 Phase diagram of wet method of deep mixing [17]

The specimens after remolding were cured in an oven with elevated temperature of $50^{\circ} \mathrm{c}$ after wrapped with aluminum foil for 7,28 dan 56 days. The main objective of using elevated temperature is to accelerate the pozzolanic reaction which is responsible for strength enhancement. The strength of the specimens was determined using unconfined compression test apparatus with strain rate of $1 \% / \mathrm{min}$.

\section{Results and Discussion}

The results of the unconfined compression test, $\mathrm{q}_{\mathrm{u}}$, were plotted to the tangent modulus at $50 \%$ of ultimate strength, $E_{50}$. The results of the specimen without additive are shown in Fig. 2. The plots showed that the deformation modulus of soil increased with increasing strength and soil with higher humic acid contents showed higher strength and deformation modulus. Hence, it suggested that the humidified organic matter (humic acid) have positive effect towards the strength and deformation modulus. However, Fig. 2(b) clearly showed that the variation of strength and deformation modulus in between replicate samples of soil without humic acid is relatively small when compared with the soil with humic acid. This finding suggested that the variability of the strength of the soil is increasing with the contents of organic matter. Correlation between the deformation modulus and ultimate strength were determined and found that soil $5 \mathrm{~K} 5 \mathrm{HA}$ was linearly correlated while the correlation of $\mathrm{E}_{50}-\mathrm{q}_{\mathrm{u}}$ of soil $10 \mathrm{~K} 0 \mathrm{HA}$ and $7 \mathrm{~K} 3 \mathrm{HA}$ were in the function of power. The correlation of deformation modulus, $\mathrm{E}_{50}$ over ultimate strength, $\mathrm{q}_{\mathrm{u}}$ for different kinds of soils are shown in Eqn. (1) - Eqn. (3) as obtained through Fig. 3. 


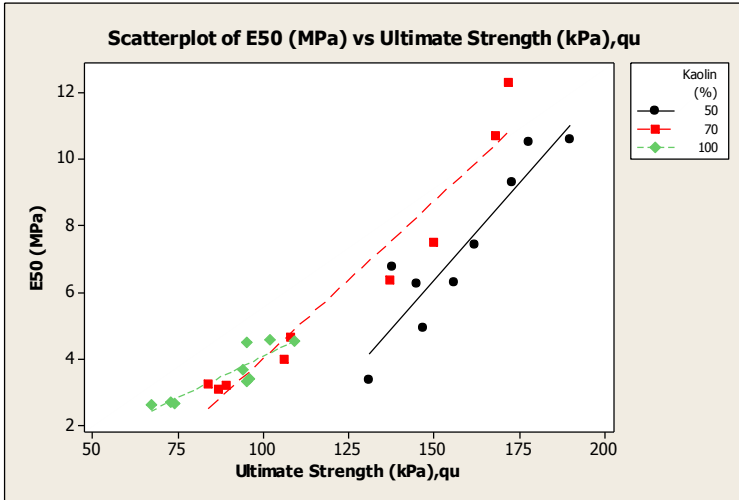

(a)

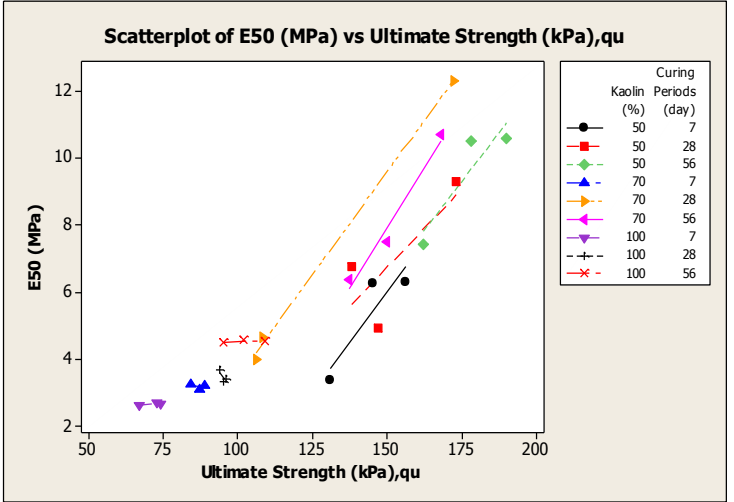

(b)

Fig. 2 Relationship of $\mathrm{E}_{50}-\mathrm{q}_{\mathrm{u}}$ (without additive)

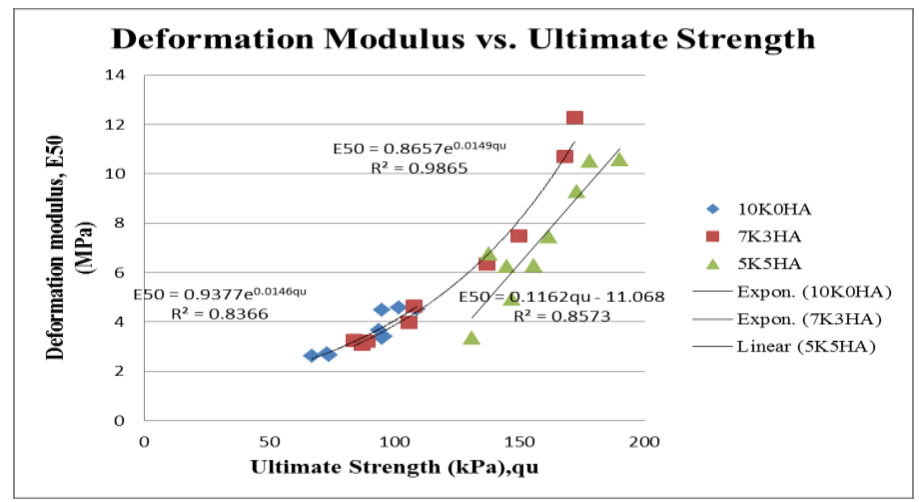

$\mathrm{E}_{50}=0.9377 \mathrm{e}^{0.0146 \mathrm{qu}}$

- Eqn.

$\mathrm{E}_{50}=0.8657 \mathrm{e}^{0.0149 \mathrm{qu}}$

- Eqn.

$\mathrm{E}_{50}=0.1162 \mathrm{qu}-$

11.068

- Eqn.

Fig. 3 Correlation of $\mathrm{E}_{50}-\mathrm{q}_{\mathrm{u}}$ (without additive)

Artificial organic soil A and B were mixed with additive in constant percentage of $12 \%$. The plot of $E_{50}$ over ultimate strength of artificial organic soils with different additive was shown in Fig. 4. It is clearly shown that effect of the additive type 3 and types 4 were almost insignificant which almost tabulated together with the artificial organic soils with no additive added. In the other hand, the additive type 1 and type 2 had shown to increase the ultimate strength and compressive modulus significantly with more than 2 times of increment. Hence, it can be explained that pozzolanic reaction should be the main contributor of the strength increment apart of the aging of soils. Pozzolanic reaction is expected to be more aggressive under the elevated temperature [8].

Besides it, the contribution of additive towards the correlation of deformation modulus and ultimate strength were shown in Fig. 5 and its formula was shown in Table 2.

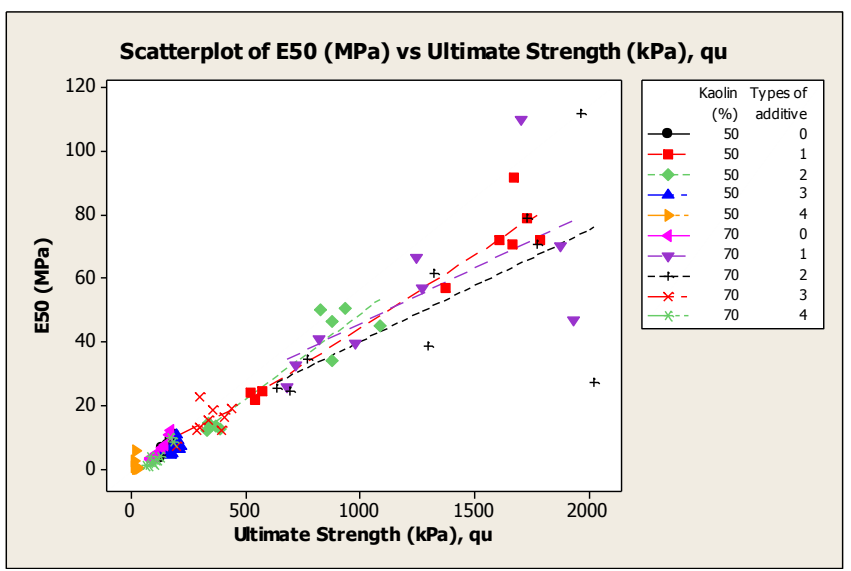

Fig. 4 Relationship of $\mathrm{E}_{50}-\mathrm{q}_{\mathrm{u}}$ (with additive) 


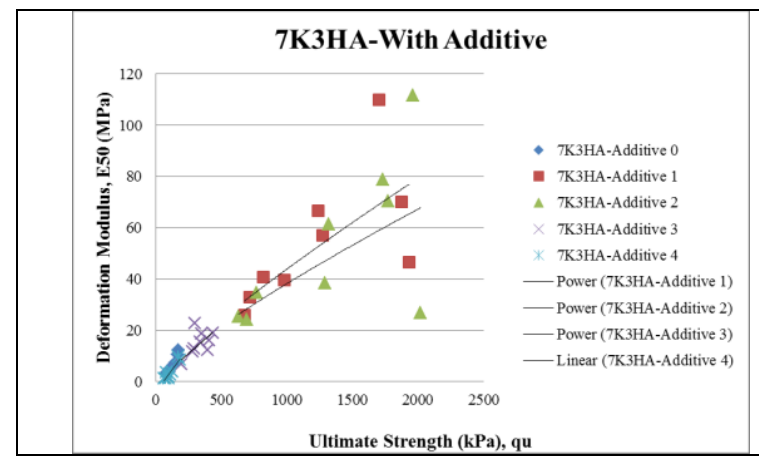

(a)

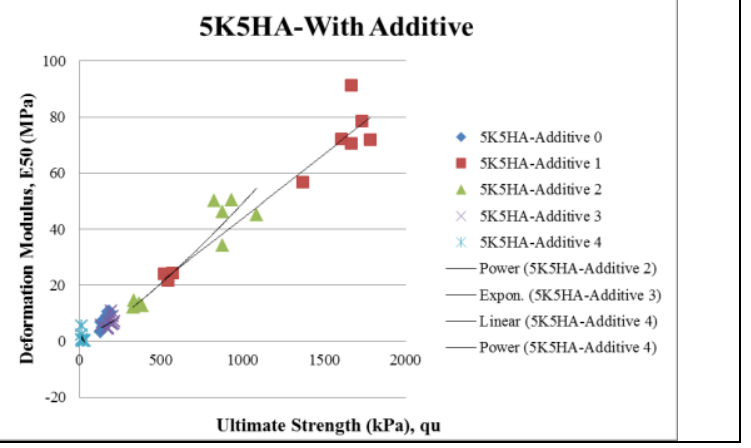

(b)

Fig. 5 Correlation of $\mathrm{E}_{50}-\mathrm{q}_{\mathrm{u}}$ (with additive)

Table 2 Correlation of deformation modulus, $\mathrm{E}_{50}$ over ultimate strength, $\mathrm{q}_{\mathrm{u}}$

\begin{tabular}{|c|c|c|c|}
\hline $\begin{array}{c}\text { Artificial organic soil } \\
\text { A with additive }\end{array}$ & Formula & $\begin{array}{c}\text { Artificial organic soil } \\
\text { B with additive }\end{array}$ & Formula \\
\hline 1 & $\mathrm{E}_{50}=0.1201 \mathrm{x}^{0.8542}$ & 1 & $\mathrm{E}_{50}=0.0337 \mathrm{x}^{1.0377}$ \\
\hline 2 & $\mathrm{E}_{50}=0.136 \mathrm{x}^{0.8161}$ & 2 & $\mathrm{E}_{50}=0.0084 \mathrm{x}^{1.2558}$ \\
\hline 3 & $\mathrm{E}_{50}=0.0384 \mathrm{x}^{1.0226}$ & 3 & $\mathrm{E}_{50}=2.2887 \mathrm{e}^{0.0056 \mathrm{x}}$ \\
\hline 4 & $\mathrm{E}_{50}=0.0698 \mathrm{x}-4.1584$ & 4 & $\mathrm{E}_{50}=1150.6 \mathrm{x}^{-2.523}$ \\
\hline
\end{tabular}

\section{Conclusion}

As a conclusion, not all types of additive will able to increase the strength and stiffness of organic soils. Additive type 1 and additive 2 which satisfy the criteria of Initial Consumption of Lime (ICL) in terms of $\mathrm{pH}$ were found to be able in increasing the strength and stiffness of soils. It was also found that low percentage replacement of lime with zeolite is effective for artificial organic soil A with lower organic contents.

\section{Acknowledgements}

The authors wish to gratefully acknowledge the financial support from Ministry of Higher Education (MOHE), Malaysia and Universiti Tun Hussein Onn Malaysia (UTHM) through FRGS Vot no. 1415.

\section{References}

[1] C. C. Wong \& C. P. Chen: Malaysia Pasture \& Forage Resource Profile, Food and Agriculture Organization of the United Nations (FAO) (2006).

[2] S. Koslanant, K. Onitsuka, \& T. Negami: Influence of Salt Additive in Lime Stabilization on Organic Clay, J. of The Southeast Asian Geotechnical Society. 37 (2006) 95-101.

[3] S. Narasimha Rao, \& G. Rajasekaran: Reaction products formed in lime-stabilized marine clays, J. Geotech Eng 122, No. 5 (1996) 329-336.

[4] F. G. Bell: Lime stabilization of clay minerals and soil, Engineering Geology 42, No. 4 (1996) 223-237. 
[5] Felix N. L. Ling, Khairul Anuar Kassim, Ahmad Tarmizi Abdul Karim and Tze Wei Chan: Stabilization of Artificial Organic Soil at Room Temperature using Blended Lime Zeolite, Advanced Materials Research Vol.723 (2013) 985-992.

[6] C. Colella, M. de' Gennaro, R. Aiello: Use of zeolitic tuff in the buiding industry, in: D.L. Bish, D.W. Ming (Eds.), Natural Zeolites: Occurrence, Properties, Applications, Reviews in mineralogy and geochemistry, Mineralogical Society of America, Washington, 2001, pp. 551588.

[7] D. I. Boardman, S. Glendinning, \& C. D. F. Rogers: Development of Stabilization and Solidification In Lime-Clay Mixes, Geotechnique 50, No. 6 (2001) 533-543.

[8] S. M. Rao \& P. Shivananda: Role of curing temperature in progress of lime-soil reactions, Geotechnical and Geological Engineering 23, No. 1 (2005) 79-85.

[9] P. Harris, O. Harvey, A. Puppala, S. Sebesta, S. R. Chikyala, and S. Saride: Mitigating The Effects of Organics In Stabilized Soils, Report No: FHWA/TX-09/0-5540-1.

[10] N. Z. Mohd Yunus, D. Wanatowski, and L. R. Stace: Effect of Humic Acid on Physical and Engineering Properties of Lime-Treated Organic Clay, Engineering and Technology 59 (2011) $1820-1825$.

[11] K. Kujala, m. Makikyro \& O. Lehto: Effect of humus on the binding reaction in stabilized soils. In Proceedings of Int. Conf. on Ground Improvement Geosystems, 2, IS-Tokyo.96: Grouting and Deep mixing, Vol. 1, Tokyo, May (1996) 415-420.

[12] N. L. L., Felix, K. A. Kassim, \& A. T. Abdul Karim: Size Distribution Analysis of Kaolin using Laser Diffraction Technique, Adv. Materials Research 341-342 (2012) 108-112.

[13] P. M. Jarret, Geoguide 6: Site Investigation for Organic Soils and Peat. JKR Document 207090341-95. Institut Kerja Raya Malaysia (1995).

[14] British Standard Institution: Stabilized materials for civil engineering purposes. BS 1924- Part 1. (1990).

[15]British Standard Institution: Stabilized materials for civil engineering purposes. BS 1924- Part 2. (1990).

[16] British Standard Institution: Unbound and hydraulically bound mixtures - Methods for the manufacture of test specimens of hydraulically bound mixtures using axial compression. BS EN 13286-53 (2004).

[17] G. M., Filz, D. K., Hodges, D. E., Weatherby, and W. A., Marr, (2005): Standardized Definitions and Laboratory Procedures for Soil-Cement Specimens Applicable to the Wet Method of Deep Mixing, Innovations in Grouting and Soil Improvement (GSP 136) in Proceedings of the Sessions of the Geo - Frontiers 2005. 